\title{
Extending role by Japanese pharmacists after training for performing vital signs monitoring
}

\author{
Fujiko HASEGAWA, Kenji HAZAMA, Shunya IKEDA, Hiroshi TAKEDA \\ Received (first version): 5 -Apr-2014 \\ Accepted: 15-Aug-2014
}

\begin{abstract}
${ }^{*}$
Background: In Japan, the circumstances in which pharmacists work are changing. Pharmacists are expected to assess conditions of patients subject to medication to ensure proper use of pharmaceutical products. To ensure fulfilment of these roles, there have already been pharmacists' efforts in performing vital signs monitoring. Objective: To clarify the necessity and related issues, by investigating the state of vital sign monitoring in clinical field by pharmacists who have been trained in vital sign monitoring.

Method: A web survey was conducted from 4 th October to 3rd December 2012, subjecting 1,026 pharmacists who completed the vital signs training hosted by The Japanese Association of Home Care Pharmacies (JAHCP). Survey items were 1) basic information of a respondent, 2) situation of homecare conducted by pharmacists, 3 ) seminar attendance status, and 4) vital signs monitoring status after the seminar.

Results: The number of valid respondents was 430 and the response rate was $41.9 \%$. As a result of the present research, it was revealed that 168 pharmacists $(41.4 \%)$, had the opportunity to perform vital signs monitoring. By conducting vital sign monitoring, effects such as 1) improved motivation of pharmacists and better communication with patients, 2) proper use of medication, and 3) cost reduction were confirmed.

Conclusion: Judging from the results of the survey, pharmacists can improve medication therapy for patients by attaining vital sign skills and conduct vital sign monitoring. Pharmacists who perform vital sign monitoring should share cases where they experienced positive patient outcomes.
\end{abstract}

Keywords: Physical Examination; Pharmaceutical Services; Professional Practice; Professional Role; Japan

\footnotetext{
"Fujiko HASEGAWA. R.Ph. MSc, MBA. Graduate School of Pharmacy, International University of Health and Welfare. Ohtawara-city, Tochigi (Japan). hu.hasegawa@suzuken.co.jp Kenji HAZAMA. MD, PhD. Chief Director, Pharmedico Co., Ltd; \& The Japan Association of Home Care Pharmacies. Kita-ku Osaka (Japan). hazaken@pharmedico.com Shunya IKEDA. MD, Dr.Med.Sci. Professor, Graduate School of Pharmacy, International University of Health and Welfare. Ohtawara-city, Tochigi (Japan). shunya@iuhw.ac.jp

Hiroshi TAKEDA. PhD. Dean, Graduate School of Pharmacy, International University of Health and Welfare. Ohtawara-city, Tochigi (Japan). hirotakeda@ iuhw.ac.jp
}

\section{INTRODUCTION}

The circumstances under which pharmacists work in Japan are changing. One of the reasons for this is that in Japan, people aged 65 years and older constitute about 25 percent of the entire population, which means that Japan has entered a time of super-aging population earlier than other countries in the world. Concerning the change in the population composition in Japan, in the society that we have today, one aged person is supported by 2.6 people in the working generation, but it is expected that in 2060 , by which time the state of the aging of the population together with the decreasing birthrate will have advanced further, one aged person will be supported by just 1.2 people in the working generation. ${ }^{1}$ The government is promoting a shift from medical care provided at hospitals to medical care provided at home for the following reasons. One is to cut medical expenditures, which are increasing due to the aging population and decreasing birthrate. The other is to respond to the rise in the number of people who wish to continue living in their own homes or at least in the same area for the remainder of their lives. As medical care at home is being promoted, pharmacists deliver medicines, check the combination of medicines that people take, check any remaining medicines, and provide other medication instructions by visiting people in their own homes and in nursing care homes, in accordance with instructions given by physicians. Medical treatment payments are made for each of these home visits by pharmacists. The number of medical service providers, such as community pharmacies, clinics and hospitals, that offer home visits by pharmacists is small due to reasons, as lack of awareness of the service and medical service providers not having sufficient pharmacists. A second reason is that further contributions by pharmacists are required because of the increasing number of medicines that require appropriate monitoring to observe their effectiveness and the occurrence of side effects because of the rise in the number of patients suffering from chronic illnesses such as diabetes and because of the development of innovative new drugs such as molecular target drugs for cancer patients. A third reason is the extension of the course term for pharmaceutical studies at college. In 2006, it was extended from four years to six years to enable pharmacy students to gain more substantial experience in a clinical environment. The first of the pharmacists to complete the six-year course started working in March 2012. Meanwhile, patient care by medical teams that makes the most 
of the expertise of various specialists, including physicians, nurses and pharmacists, is being promoted. On April 30, 2011, the Ministry of Health, Labour and Welfare issued a notification titled, Promotion of Medical Care by Medical Teams through the Collaboration and Coordination of Medical Staff. As experts in medication, pharmacists are expected to realize the optimal use of medicines and medical supplies by people on medication. This point is clearly stated in the updated version of Good Pharmacy Practice entitled Joint FIP/WHO Guidelines on Good Pharmacy Practice: Standards for Quality of Pharmacy Service issued by the International Pharmaceutical Federation (FIP) and the World Health Organization (WHO) in 2011. ${ }^{2}$ Therefore, the course of action that pharmacists in Japan are trying to take leads to the fulfillment of duties that are common among pharmacists all over the world.

One example of proactive involvement by pharmacists that is stated in the notification of the Ministry of Health, Labour and Welfare is pharmaceutical management (including monitoring the state of any side effects that patients are experiencing and providing medication instructions) for patients on pharmacotherapy (including such patients receiving treatment at home). Efforts are being made so that pharmacists can check vital signs and make physical assessments as a means of pharmaceutical management. The number of pharmaceutical colleges that include vital sign training programs in the curricula of the six-year pharmaceutical courses is increasing. ${ }^{3}$ However, the number of hospitals, clinics and pharmacies whose pharmacists carry out vital sign monitoring and physical assessments is small, because most of their pharmacists completed only four years of pharmaceutical education and did not receive the training. Instructors at pharmacy schools are trying to improve training programs by using means such as giving questionnaires to students, because they are not sure whether students will be able to use the skills they acquire through training in the future at work. Spray et al. ${ }^{4}$ stated, "Since patient assessment skills are part of the everyday practice of pharmacists, it is important that pharmacy students are properly trained with these skills". Also, Bolesta et al. ${ }^{5}$ reported on a study of the physical assessment curricula by pharmacists for pharmacy students. As written above, efforts are also being made overseas to establish an effective education for physical assessment.

The purpose of physical assessments by pharmacists is to contribute to the proper use of medicines, such as, improving medication efficacy or early detection of side effects of medicines by checking the state of patients after administering medicines. Jones defines patient assessment by pharmacists as the process by which information is gathered from the patient and other sources and evaluated in order to make decisions regarding: (1) the health status of the patient; (2) drug therapy needs and problems and prevent future problems; (3) interventions that will resolve identified drug problems and prevent future problems; and (4) follow-up to ensure that patient outcomes are being met. $^{6}$

However, at clinical sites, physicians, nurses and other specialists do the work of monitoring vital signs. Arguments both for and against the necessity of vital sign monitoring by pharmacists have been reported $^{7,8}$, which is the same situation as exists in Japan. There are few reports on the proportion of pharmacists actually performing physical assessments by monitoring vital signs at clinical sites. Barry et al. investigated the changes in the work of pharmacists after they had received physical assessment training, and found that they did not begin to do physical assessments at work, but that their confidence was significantly raised. ${ }^{9}$

According to a questionnaire survey that the Japanese Society of Hospital Pharmacists conducted with 6,747 hospitals all over Japan as subjects (effective response rate of $47.1 \%)^{10}$, between $4-5 \%$ of hospitals that responded to the survey stated that their pharmacists monitor vital signs and make physical assessments for the prevention of side effects and other purposes. Concerning pharmacists working at pharmacies, Oshima et al. ${ }^{11}$ reported that their physical assessments of people who were living in health facilities specialized for the elderly in need of nursing care and who were being treated with antihypertensive medicines contributed to enhancement of the effectiveness of the medicines and reduction in the costs expended on medicines. A consciousness survey of pharmacy students and pharmacists who participated in a vital sign workshop confirmed the high requirement for vital sign monitoring. ${ }^{12}$ There are no reports of any nationwide surveys into the relevant activities at clinical sites, including pharmacies. Therefore, a decision was made to clarify both the necessity and the problems of vital sign monitoring and physical assessment by pharmacists, so that pharmacists will become able to carry out vital sign monitoring and physical assessment in their work. This clarification was accomplished by investigation the state of the performance of such after they had received vital sign training.

\section{METHODS}

\section{Survey subjects}

Subjects are all of the pharmacists participating in the Japan Association of Home Care Pharmacies (JAHCP) seminars during this timeframe (2012-). Public bodies have not established vital sign training programs for pharmacists, so the JAHCP which offers systematic vital sign training on a continuous basis, was requested to provide cooperation.

In this paper, the vital signs that pharmacists monitor are defined as blood pressure, respiration, pulse, cardiac sound, intestinal sound, body temperature, consciousness and urinary volume.

JAHCP offers four levels of seminars: the first-level seminar is called the Vital Sign Seminar; the second level, Instructor Seminar 1; the third level, Instructor Seminar 2; and the fourth-level is called the Director 
Seminar. Vital signs monitoring training is performed in pairs without using a physical assessment model of a simulator.

\section{Survey items}

The author carefully prepared the questions for the questionnaire after attending the Vital Sign Seminar of JAHCP on July 7,2012 , and hearing the opinions of several directors.

The questionnaire included the following questions: (1) basic information about the respondents (gender, employer, age group and region), (2) the state of participation in medical care at home by pharmacists working at pharmacies, (3) the state of participation in the seminars provided by JAHCP (qualifications granted by JAHCP, who bears the costs of seminars and previous participation in any other seminars), (4) the state of conducting vital sign monitoring after receiving seminars (willingness to perform vital sign monitoring, whether or not they have performed vital sign monitoring and, if yes, on what occasion, the vital sign monitoring skills used, the effectiveness of vital sign monitoring, continuous performance of vital sign monitoring, factors obstructing the performance of vital sign monitoring), and (5) any requests for vital sign seminars. With regard to 'willingness to perform vital sign monitoring' in question (4), the state of conducting vital sign monitoring after receiving seminars, five choices (1. wanting to do vital sign monitoring immediately, 2 . wanting to make preparations to do vital sign monitoring, 3. wanting to do vital sign monitoring but thinking it will be difficult to do so for the time being, 4. not wanting to do vital sign monitoring, and 5. already doing vital sign monitoring) were given in order to survey such willingness after receiving seminars. For question (5), any requests for vital sign seminars, respondents were allowed to respond freely.

\section{Survey method}

The survey was conducted for two months from October 4 to December 3, 2012 with 1,026 pharmacists who participated in a vital sign seminar provided by JAHCP as the subjects. The survey was carried out through JAHCP using a website.

\section{Analysis method}

A chi-square test was performed for gender, age group, employer, the state of participation in medical care at home (pharmacists working at pharmacies only), region, qualifications granted by JAHCP, who bears the costs of seminars, previous participation in any other seminars and willingness to perform vital sign monitoring in order to clarify matters related to whether or not vital sign monitoring is performed. Statistical analysis was conducted using IBM SPSS Statistics 19 with a significance level set at 0.05 .

\section{Ethical considerations}

This survey research was conducted with the approval of the ethics committee of the International University of Health and Welfare (approval no: 1295). The purpose of the research, the survey method and other matters were explained in detail

\begin{tabular}{|c|c|}
\hline Item & Number responses (\%) \\
\hline $\begin{array}{r}\text { Male } \\
\text { Female }\end{array}$ & $\begin{array}{l}227(55.9 \%) \\
179(44.1 \%)\end{array}$ \\
\hline $\begin{array}{r}\text { Age group } \\
\qquad \begin{array}{r}20-29 \\
30-39 \\
40-49 \\
50-59 \\
60 \text { and older }\end{array} \\
\begin{array}{r} \\
4\end{array} \\
\\
4\end{array}$ & $\begin{array}{c}43(10.6 \%) \\
177(43.6 \%) \\
113(27.8 \%) \\
61(15.0 \%) \\
12(3.0 \%)\end{array}$ \\
\hline $\begin{array}{l}\text { Workplace } \\
\text { Hospital } \\
\text { Community pharmacy }\end{array}$ & $\begin{array}{c}73(18.0 \%) \\
333(82.0 \%)\end{array}$ \\
\hline
\end{tabular}

to JAHCP, who gave their consent. A linked site for the website questionnaire was prepared and notified to members of JAHCP by using their membership mailing list. The questionnaire had a clear statement that individuals would not be identified and that results would be published by means such as an academic paper, and the respondents were requested to answer the questions only if they agreed with the conditions.

\section{RESULTS}

\section{Recovery rate}

There were 448 responses, but 18 of these were duplicated by respondents, so the number of valid responses was 430 , and the valid response rate was $41.9 \%(430 / 1,026)$. Among the 430 people who responded to the survey out of the 1,026 recipients of the survey, 406 were pharmacists who worked at clinical sites (hospitals or pharmacies) and were in direct contact with patients. The subjects of this analysis were these 406 people out of the 1,026 recipients of the survey.

\section{Basic information of the respondents}

The attributes of the respondents are as shown in Table 1. The locations of their places of work were categorized into nine groups based on the prefectural codes of JIS X0401 as shown in Figure 1. [These are codes set for local governments in Japan, and are used for the processing of statistics, such as national censuses]. Nearly half of the subjects worked in the Kanto and Kinki regions, but places of work were distributed nationwide.

\section{State of participation in medical care at home by pharmacists working at pharmacies}

Among 333 subject pharmacists working at pharmacies (excluding 73 subject pharmacists working at hospitals), 208 pharmacists (62.5\%) participated in home medical care, 124 pharmacists $(37.5 \%)$ did not, and 1 pharmacist $(0.3 \%)$ did not respond.

\section{State of participation in the seminars provided by JAHCP}

The state of participation in the seminars provided by JAHCP is as shown in Table 2. Out of the 406 recipients of the survey, the total number of pharmacists who participated in a Vital Sign Seminar and pharmacists who participated in Instructor Seminar 1 was 352 , which was $86.7 \%$ of the entire subjects. Out of the 406 recipients of the 


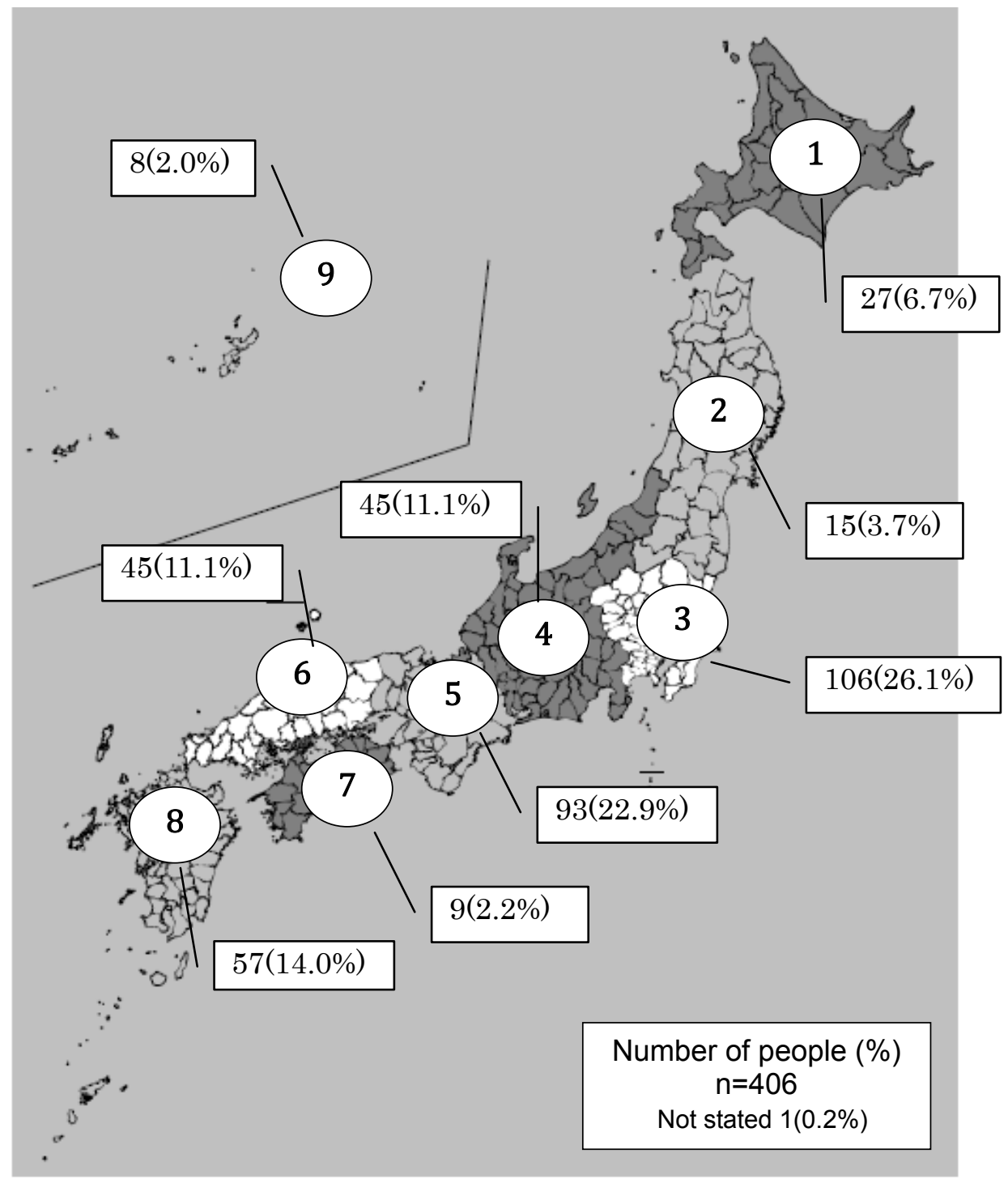

Figure 1. Workplace location.

(1) Hokkaido (2) Tohoku (3) Kanto (4) Chubu (5) Kinki (6) Chugoku (7) Shikoku (8) Kyushu (9) Okinawa

survey, 114 pharmacists $(28.1 \%)$ participated in vital sign seminars provided by organizations other than JAHCP. Concerning the costs of participating in seminars, 220 pharmacists $(54.2 \%)$ paid all of the costs themselves and $46(11.5 \%)$ paid part of the costs, the total of which was about two-thirds of the entire subjects.

\section{General state of conducting vital sign monitoring after receiving training}

\section{WHETHER OR NOT VITAL SIGNS WERE MONITORED}

After receiving vital sign training, out of the 406 recipients of the survey, 168 pharmacists (41.4\%) stated that they had had chances to monitor vital signs, and $238(58.6 \%)$ stated that they had not. Among the 168 pharmacists who had had the chances, 129 continued to monitor vital signs. The differences between the pharmacists who monitored vital signs and those who did not are shown in Table 3 . There were significant differences in the percentages of pharmacists who conducted vital sign monitoring broken down by age group, qualifications, previous participation in other seminars, willingness to perform vital sign monitoring and the state of participation in medical care at home (pharmacies only).

The correlation between the percentages of pharmacists who conducted vital sign monitoring and their willingness to do so was studied. Thirtyfour pharmacists who already been performing monitoring were excluded. The percentage of

\begin{tabular}{|c|c|}
\hline item & Number responses (\%) \\
\hline \multicolumn{2}{|l|}{ JAHCP qualifications } \\
\hline Beginner Level & $321(79.1 \%)$ \\
\hline Instructor Level 1 & $31(7.6 \%)$ \\
\hline Instructor Level 2 & $14(3.4 \%)$ \\
\hline $\begin{aligned} \text { Director Level } \\
\end{aligned}$ & $40(9.9 \%)$ \\
\hline \multicolumn{2}{|l|}{ Who paid course cost? } \\
\hline Fully self-funded & $220(54.2 \%)$ \\
\hline Partially self-funded & $46(11.3 \%)$ \\
\hline Fully company-funded & $140(34.5 \%)$ \\
\hline \multicolumn{2}{|l|}{$\begin{array}{l}\text { Have you attended other } \\
\text { courses? }\end{array}$} \\
\hline Yes & $114(28.1 \%)$ \\
\hline No & $292(71.9 \%)$ \\
\hline
\end{tabular}




\begin{tabular}{|c|c|c|c|}
\hline item & Implemented (\%) & Not implemented (\%) & P-value \\
\hline $\begin{array}{r}20-29 \\
30-39 \\
40-49 \\
50-59 \\
60 \text { and older } \\
\end{array}$ & $\begin{array}{c}10(23.3 \%) \\
71(40.1 \%) \\
49(43.4 \%) \\
32(52.5 \%) \\
6(50.0 \%) \\
\end{array}$ & $\begin{array}{c}33(76.7 \%) \\
106(59.9 \%) \\
64(56.6 \%) \\
29(47.5 \%) \\
6(50.0 \%) \\
\end{array}$ & 0.048 \\
\hline Home care & $\begin{array}{c}113(54.3 \%) \\
32(25.8 \%)\end{array}$ & $\begin{array}{l}95(45.7 \%) \\
92(74.2 \%)\end{array}$ & $<0.001$ \\
\hline $\begin{array}{l}\text { Qualification } \\
\qquad \begin{array}{r}\text { Beginner Level } \\
\text { Instructor Level 1 } \\
\text { Instructor Level } 2 \\
\text { Director Level }\end{array} \\
\end{array}$ & $\begin{array}{l}115(35.8 \%) \\
15(48.4 \%) \\
11(78.6 \%) \\
27(67.5 \%) \\
\end{array}$ & $\begin{array}{c}206(64.2 \%) \\
16(51.6 \%) \\
3(21.4 \%) \\
13(32.5 \%) \\
\end{array}$ & $<0.001$ \\
\hline $\begin{array}{r}\text { Have you attended other courses? } \\
\text { Yes } \\
\text { No }\end{array}$ & $\begin{array}{c}65(57.0 \%) \\
103(35.3 \%)\end{array}$ & $\begin{array}{c}49(43.0 \%) \\
189(64.7 \%)\end{array}$ & $<0.001$ \\
\hline $\begin{array}{r}\text { Willingness to use } \\
\text { Will use immediately } \\
\text { Am preparing to use } \\
\text { Want to use, but difficult at present } \\
\text { Do not want to use }\end{array}$ & $\begin{array}{c}85(86.4 \%) \\
37(32.3 \%) \\
14(10.8 \%) \\
1(14.3 \%)\end{array}$ & $\begin{array}{c}14(13.6 \%) \\
80(67.7 \%) \\
135(89.2 \%) \\
6(85.7 \%)\end{array}$ & $<0.001$ \\
\hline
\end{tabular}

pharmacists who actually conducted vital sign monitoring among those who wanted to do so immediately was $86.4 \%$; the percentage of pharmacists who wanted to make preparations to do the monitoring was $32.3 \%$, the percentage of pharmacists who wanted to do the monitoring but thought it would be difficult to do so for the time being was $10.8 \%$, and the percentage of pharmacists who did not want to do the monitoring was $14.3 \%$. An analysis of the correlation between the percentages of pharmacists who conducted vital sign monitoring and their willingness to do so showed that the more positive the pharmacists were, the more they actually carried out vital sign monitoring $(P<0.001)$. There was a significant difference in the percentages of pharmacists who conducted vital sign monitoring between pharmacies that participated in medical care at home and those that did not $(\mathrm{P}<0.001)$.

\section{PHARMACISTS WHO MONITOR VITAL SIGNS}

The 168 pharmacists who had chances to monitor vital signs were asked on which occasions they had done so, with multiple answers allowed. As shown in Table 4, 100 pharmacists -- the largest number, chose 'when providing medication instructions at patients' homes, on behalf of dispensing pharmacies'; 68 chose 'when providing medication instructions at dispensing pharmacies'; 22 chose 'while on ward duty at hospitals'; and one chose 'when providing medication instructions at patients' homes, on behalf of hospitals'. This showed that pharmacists monitored vital signs when providing medication instructions not only at patients' homes but also at pharmacies. The monitoring skills shown performance listed in Table 5. At pharmacies, simple monitoring was mainly performed, including monitoring of the pulse and edema, and measuring of $\mathrm{SpO}_{2}$. On the other hand, monitoring the breath and bowels sounds using stethoscopes was performed more frequently during ward duty at hospitals than at pharmacies. Pharmacists also noted that they monitored irregular pulses using electrocardiograms, measured glucose levels, performed oral checking, visually checked the entire body for athlete's foot, dry skin, etc., and other physical assessments.

\section{POSITIVE RESULTS OF VITAL SIGN MONITORING}

The 168 pharmacists who had had chances to monitor vital signs were asked to choose among outcomes of interventions with multiple answers allowed. As shown in Table 6, 118 pharmacists -the largest number, chose 'improvement in communications with patients', 108 chose 'rise of your own motivation' and 24 chose 'rise in adherence'. Asked about the positive results of vital sign monitoring, 22 pharmacists chose 'early detection of side effects', 27 chose 'change of prescriptions' and 7 chose 'cost cutting'.

\section{OBSTRUCTING FACTORS FOR PHARMACISTS WHO HAD NOT HAD CHANCES TO MONITOR VITAL SIGNS}

The 238 pharmacists who did not conduct vital sign monitoring at clinical sites were asked for the reasons for not doing so, with multiple answers allowed. As Table 7 shows, 127 pharmacists -- the largest number, chose "no opportunities to conduct vital sign monitoring (no opportunities)', 54 chose 'insufficient ability to make assessments after vital sign monitoring (insufficient ability to make assessments)', 52 chose 'not confident to conduct

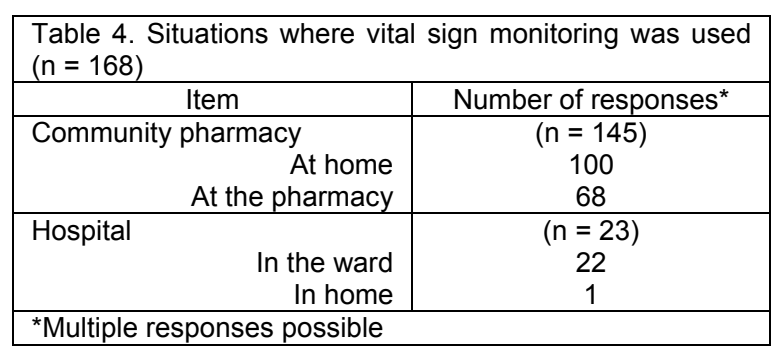




\begin{tabular}{|c|c|c|c|}
\hline \multirow{2}{*}{ Item } & \multicolumn{3}{|c|}{ Number of responses $(\% \text { included in } n)^{\star}$} \\
\hline & Overall & Community pharmacies & Hospitals \\
\hline Number & 168 & 145 & 23 \\
\hline Pulse rate & $122(72.6 \%)$ & $106(73.1 \%)$ & $16(69.6 \%)$ \\
\hline $\mathrm{SpO}_{2}$ & $101(60.1 \%)$ & $87(60.0 \%)$ & $14(64.7 \%)$ \\
\hline Edema & $91(54.2 \%)$ & $75(51.7 \%)$ & $16(69.6 \%)$ \\
\hline Automatic blood pressure monitor & $77(45.8 \%)$ & $70(48.3 \%)$ & $7(30.4 \%)$ \\
\hline Mercury blood pressure gauge & $72(42.9 \%)$ & $69(47.6 \%)$ & $3(13.0 \%)$ \\
\hline Body temperature measurement & $57(33.9 \%)$ & $51(35.2 \%)$ & $6(26.1 \%)$ \\
\hline Stethoscope respiratory sounds & $47(30.0 \%)$ & $37(25.5 \%)$ & $10(43.5 \%)$ \\
\hline Stethoscope bowel sounds & $39(23.2 \%)$ & $28(19.3 \%)$ & $11(47.8 \%)$ \\
\hline Stethoscope cardiac sound & $26(15.5 \%)$ & $23(15.9 \%)$ & $3(13.0 \%)$ \\
\hline Other & $11(6.5 \%)$ & $10(6.9 \%)$ & $1(4.3 \%)$ \\
\hline
\end{tabular}

vital sign monitoring (not confident)' and 51 chose 'objections from other medical staff working together'. All of the 51 pharmacists who chose 'objections from other medical staff working together' thought physicians would object.

With regard to willingness to perform vital sign monitoring after participating in a seminar, of the pharmacists who chose 'no opportunities', 4 pharmacists chose 'wanting to do vital sign monitoring immediately', 41 chose 'wanting to make preparations to do vital sign monitoring', 78 chose 'wanting to do vital sign monitoring but thinking it will be difficult to do so for the time being' and 2 chose 'not wanting to do vital sign monitoring'. The following are examples of matters noted in freeform responses that the pharmacists who chose 'no opportunities' would like to be added to the seminars provided by JAHCP: 'wanting to hear about the experiences and problems from people who are making physical assessments'; 'learning the workflow beginning from visiting a home, performing vital sign monitoring, to making a report to a physician, and examples of such actions'; and 'an opportunity to think about what is required to gain the understanding and cooperation of patients and hospital staff after performing vital sign monitoring at pharmacies'.

\section{DISCUSSION}

\section{State of conducting vital sign monitoring}

In Japan, the main duty of pharmacists is to accurately prepare medicines as prescribed by physicians and to dispense medicines to patients. According to the result of a survey conducted by the Japan Pharmaceutical Association with hospitals as subjects, only at a few percent of hospitals are pharmacists allowed to be in contact with patients and to do vital sign monitoring. There is a body of opinion that there is little need for pharmacists to conduct vital sign monitoring at clinical sites, because other medical staff regularly monitor vital signs. On the other hand, this survey revealed that about $40 \%$ of responding pharmacists who work at clinical sites conduct vital sign monitoring. The percentage of pharmacists who work at pharmacies that are involved in medical care at patient's home and who perform vital sign monitoring is considerably high. The greatest number of pharmacists stated that they monitored vital signs 'when providing medication instructions at patients' homes, on behalf of dispensing pharmacies'. From this, it can be understood that vital sign monitoring by pharmacists is required for home medical care. The proportion of pharmacists conducting vital sign monitoring is expected to rise, because the number of local pharmacies that participate in home medical care will rise due to the promotion of home medical care. Home medical care includes care at facilities and at patients' homes. In medical care by medical teams, vital sign monitoring by pharmacists for aged people who live alone at their homes is considered to be particularly effective because the aged people are carefully watched.

At pharmacies, the pharmacists performed simple monitoring, including monitoring of the pulse and edema, and measuring of $\mathrm{SpO}_{2}$. Since performing this monitoring is very simple, these would not be much difference in the results from those obtained by more specialized health care workers. Some pharmacists stated that they monitored irregular pulses using electrocardiograms, measured glucose levels, etc., which are not taught in JAHCP's seminars. The authors' think that extent to which pharmacists should conduct vital sign monitoring should be determined by legislation.

\section{Effectiveness after conducting vital sign monitoring}

Yamamoto, vice president of Japan Pharmaceutical Association, said that pharmacists who have little experience in dealing with patients directly have a small impact on both patients and medical service

Table 6. Events where performing vital signs check led to positive effect $(n=168)^{*}$

\begin{tabular}{|l|c|}
\hline \multicolumn{1}{|c|}{ Item } & Responses \\
\hline Improved communication with patient & 118 \\
\hline Improved self-motivation & 108 \\
\hline Improved communication with physician & 39 \\
\hline Improved communication with nurse & 33 \\
\hline $\begin{array}{l}\text { Improved communication with other } \\
\text { professionals }\end{array}$ & 28 \\
\hline Prescription change & 27 \\
\hline Recommended patient consultation & 26 \\
\hline Improved patient adherence & 24 \\
\hline Early discovery of adverse reactions & 22 \\
\hline $\begin{array}{l}\text { Improved motivation of pharmacy as a } \\
\text { whole }\end{array}$ & 22 \\
\hline Nothing at present & 19 \\
\hline Reduced costs & 8 \\
\hline Other & \\
\hline *Multiple responses possible & \\
\hline
\end{tabular}




\begin{tabular}{|l|c|}
\hline \multicolumn{2}{|l|}{$\begin{array}{l}\text { Table 7. Reason why vital sign monitoring (or vital signs } \\
\text { check) was not possible }(\mathrm{n}=238)^{*}\end{array}$} \\
\hline \multicolumn{1}{|c|}{ Item } & Responses \\
\hline No opportunity to use & 127 \\
\hline Do not use in current duties & 73 \\
\hline Lack of assessment ability & 54 \\
\hline Lack of confidence & 51 \\
\hline $\begin{array}{l}\text { Understanding of surrounding health } \\
\text { professionals }\end{array}$ & 38 \\
\hline Lack of time & 32 \\
\hline Obtain information from other employees & 9 \\
\hline Understanding of patient or their family & 18 \\
\hline Other & \\
\hline${ }^{*}$ Multiple responses possible & \\
\hline
\end{tabular}

providers. ${ }^{13}$ However, after pharmacists conducted vital sign monitoring, they indicated that their motivation for professional work increased. This improved motivation will be a greater stimulus than anything else to pharmacists to become proactive in their profession. Improving communications with patients will facilitate receiving information from patients, which is expected to contribute to maximizing the effectiveness of medicines. The effectiveness in raising adherence is also noteworthy. Problems related to adherence have been studied as common problems internationally. ${ }^{14-17}$ According to a WHO report published in 2003, only 50 percent of patients suffering from chronic illnesses adhere to instructions. ${ }^{18-20}$ In Japan, it is reported that the value of medicines that remain unused in the homes of the aged reaches about 50 billion Japanese Yen a year, which has become a social problem. ${ }^{21}$ If the way in which people use medicines could be improved worldwide, this would eliminate the waste of USD500 billion a year that arises from the improper use of medicines. It is said that improvement in adherence alone would reduce the waste by USD269 billion, which is more than half of the entire waste of USD500 billion, and constitutes $8 \%$ of the entire medical care expenditure of the world. Strengthening of the use of pharmacists in medication management is proposed from a global point of view. $^{22}$

There are reports of cases in which pharmacists contributed to early detection of the side effects of medicines and to the proper use of medicines by monitoring vital signs and passing on information to physicians. Physicians attach importance to the effectiveness of medicines; whereas pharmacists always bear in mind the prevention and early detection of the side effects of medicines because of differences in their duties in medical care. Cooperation between physicians and pharmacists is expected to lead to the effectiveness and safety of pharmacotherapy for patients.

Based on the results of this questionnaire survey, it is considered that vital sign monitoring by pharmacists is required in order to reduce the side effects of medicines and to ensure the proper use of medicines.

\section{Problems related to vital sign monitoring}

The survey revealed that the following problems hinder the promotion of vital sign monitoring and physical assessments by pharmacists.
The first problem is that many pharmacists consider that there are 'no opportunities'. Although there are many possible reasons for this, one major reason is that people are not sure about the effectiveness of vital sign monitoring by pharmacists. To solve this problem, proactive sharing of information, including information of cases where the monitoring generated positive results and of experiences and problems of the monitoring, will be effective.

The second problem is that pharmacists are 'not confident' and are of the belief that they have 'insufficient ability to make assessments'. Concerning basic skills taught at seminars provided by JAHCP, as pharmacists participate in these seminars more, pharmacists express the state of 'not confident', so it was thought that fewer pharmacists would have confidence after having practice and gaining experience. However, the scope and levels of skills required by pharmacists are not established, and the content and levels of seminars provided by various institutions differ. Clarification of the vital sign monitoring skills that pharmacists should have is required. A major issue is how to make assessments by connecting the results of vital sign monitoring with medicines. In the US, $96 \%$ of doctoral courses in pharmacy offer training in physical assessment skills including vital sign monitoring. ${ }^{4}$ A future goal for pharmacy in Japan is the establishment of a systematic training system that includes further learning after graduation.

The third problem is not having the understanding of other medical professionals. At vital sign seminars provided by JAHCP, conveying of the meaning and the purpose of vital sign monitoring by pharmacists to participants is emphasized. It is crucial for pharmacists to understand the purpose and meaning of their monitoring vital signs and to clearly convey the purpose to physicians and patients, and after receiving their consent to carry out vital sign monitoring. It is of primary importance that pharmacists always endeavor to maintain good communications and be proactively involved in medical care to enhance this understanding.

\section{Limitations of the Research}

The subjects of this survey are limited to pharmacists who proactively participated in vital sign seminars conducted by JAHCP, and do not represent all pharmacists. Furthermore, information about the level of training for each pharmacist respondent was not available.

Also, more than half of the pharmacists did not respond to this survey. There is no information on whether or not they were interested in vital sign monitoring or had experience in that area. Therefore, there might be a little bias involved. We would also like to have surveys of pharmacists who participated in other seminars and surveys on patients whose vital signs were actually monitored by a pharmacist.

In order to verify the results of vital sign monitoring, it is important that not only information be gathered on examples related to prescription suggestions to pharmacists but also that research be conducted 
before and after vital sign monitoring is performed and that research be conducted on whether or not vital sign monitoring has been performed.

\section{CONCLUSIONS}

In addition to their current work in preparing drugs, pharmacists are expected to demonstrate their expertise from a new aspect whereby they check whether or not drugs they prepare and administer to patients are properly used. Vital sign monitoring is considered beneficial in this new work.

In order to broaden the scope, payment must be through payment for physical assessment monitoring conducted by pharmacists, and it is essential that further evidence be gathered for that purpose.

\section{ACKNOWLEDGMENTS}

The authors are sincerely grateful to pharmacists nationwide who gave their time to respond to the survey, and to Ms. Kiyoko Takasaki from Takasa Co., Ltd., who helped so much in the preparation of the questionnaire.

\section{CONFLICT OF INTEREST}

The first author F.H. is an employee of a wholesaler of drugs called Suzuken Co., Ltd.. None of the authors have any conflicts of interest associated with this study.

Funding: This research received no specific grant from any funding agency in the public, commercial, or not-for-profit sectors.

\section{RESUMEN}

Antecedentes: En Japón, las circunstancias en las que trabajan los farmacéuticos están cambiando. Se espera que los farmacéuticos evalúen los problemas de salud que están siendo tratados con medicación para asegurar el uso adecuado de los medicamentos. Para asegurar el cumplimiento de este papel, los farmacéuticos han iniciado esfuerzos para realizar monitorización de signos vitales.

Objetivo: Clarificar la necesidad y problemas asociados, investigando el estado de la monitorización de signos vitales en la práctica clínica por farmacéuticos que fueron entrenados en monitorización de signos vitales.

Método: Se realizó un cuestionario online de 4 de octubre a 3 de diciembre de 2012, alcanzando a 1.026 farmacéuticos que habían completado el entrenamiento en signos vitales realizado por la Asociación Japonesa de Farmacias Comunitarias (JAHCP). Los ítems del cuestionario fueron. 1) información básica del encuestado, 2) situación de la atención domiciliaria realizada por farmacéuticos, 3) situación de la asistencia al seminario, y 4) estado de la monitorización de signos vitales después del seminario.

Resultados: El número de respondentes válidos fue de 430 y la tasa de respuesta fue del $41,9 \%$. Como resultado de esta investigación, se descubrió que 168 farmacéuticos $(41,4 \%)$ tuvo la oportunidad de realizar monitorización de signos vitales. Al realizar monitorización de signos vitales se confirmaron efectos tales como 1) mejora de la motivación delos farmacéuticos y mejor comunicación con los pacientes, 2) uso adecuado de la medicación, y 3 ) reducción de costes.

Conclusión: Juzgando los resultados de la encuesta, los farmacéuticos pueden mejorar el tratamiento medicamentosos de los pacientes mediante la adquisición de habilidades en signos vitales y realizando monitorización de signos vitales. Los farmacéuticos que realizan monitorización de signos vitales deberían compartir los casos que hayan visto de resultados positivos de pacientes.

Palabras clave: Examen Físico; Servicios

Farmacéuticos; Ejercicio profesional; Rol Profesional; Japón

1. Ministry of Health, Labor and Welfare, Promotion of long-term care and home care http://www.mhlw.go.jp/stf/seisakunitsuite/bunya/kenkou iryou/iryou/zaitaku/index.htm (Accessed 26-Nov-2013).

2. FIP/WHO Joint Statement on the role of Pharmacists in Tuberculosis Care and Control. http://www. fip.org/www/uploads/database file.php?id=347\&table id= (Accessed 26-Nov-2013).

3. Utsumi M, Tokunaga J, Yamaoka Y, Takamura N. Status of Clinical Skills Education in Faculties of Pharmaceutical Sciences in Japan. J Pharm Health Care Sci. 2010;36(9):657-666 [In Japanese].

4. Spray JW, Parnapy SA. Teaching patient assessment skills to doctor of pharmacy students: the TOPAS study. Am J Pharm Educ. 2007;71(4):64.

5. Bolesta S, Trombetta DP, Longyhore DS. Pharmacist Instruction of Physical Assessment for Pharmacy Students. Am J Pharm Educ. 2011;75(2):29.

6. Jones RM. Patient assessment and the Pharmacist's role in patient care. In: Jones RM, Rospond RM, eds. Patient Assessment in Pharmacy Practice.2nd ed. Philadelphia,PA: Lippincott,Willams,\& Wilkins; 2009: p. 2-11.

7. Simpson SH. Should pharmacists perform physical assessments? The "pro" side. Can J Hosp Pharm. 2007;60(4):271272.

8. Wilson B. Should pharmacists perform physical assessments? The "con" side. Can J Hosp Pharm. 2007;60(4):272-273.

9. Barry AR, McCarthy L, Nelson CL, Pearson GJ. An evaluation of teaching physical examination to Pharmacists. Can Pharm J (Ott). 2012;145(4):174-179.e1. doi: 10.3821/145.4.cpj174

10. Physical assessments for ensuring safe drug therapy. Yakuji Nippo March 2010; No. 10.

11. Ohshima S, Oda A, Yoshida T, Kodaira S, Shibata M, Ogawa I, Ohno Y, Yamamoto K, Shirahata A, Kobayashi D. Pharmacist Intervention Involving Physical Assessment in Reviewing Prescriptions for Antihypertensive Medication. Pharmacy Society of Japan.2011;3(1):39-44 [In Japanese]. 
12. Tokunaga J, Takamura N, Ogata K, Setoguchi N, Maruta E. Implementation of workshop for pharmacists on confirmation of vital signs and attitude survey of participating pharmacists. J Kyushu Univ Health Welfare. 2011;12:183188 [In Japanese].

13. Yamamoto N. A pharmacy pharmacist's future view. Med Drug J..2011;47(7):1865-1869 [In Japanese].

14. Mathes T, Pieper D, Antoine SL, Eikermann M. $50 \%$ adherence of patients suffering chronic conditions-where is the evidence?. Ger Med Sci. 2012;10:Doc16. doi: 10.3205/000167

15. Brown MT, Bussell JK. Medication adherence: WHO cares?. Mayo Clin Proc. 2011;86(4):304-14. doi: 10.4065/mcp.2010.0575

16. Osterberg L, Blaschke T. Adherence to Medication. N Engl J Med. 2005;353(5):487-497.

17. Nakai K, Yamamoto N, Kamei M, Fujita M. The effect of one-dose package on medication adherence for the elderly care in Japan. Pharm Pract (Granada). 2009;7(1):59-62.

18. World Health Organization. Adherence to long-term therapies: evidence for action.Geneva: WHO; 2003. http://whqlibdoc.who.int/publications/2003/9241545992.pdf (Accessed 28-Oct-2013).

19. Sackett DL, Haynes RB, Gibson ES, Hackett BC, Taylor DW, Roberts RS, Johnson AL. Randomised clinical trial of strategies for improving medication compliance in primary hypertension. Lancet. 1975;1(7918):1205-1207.

20. Lipman RS, Rickels K, Uhlenhuth EH, Park LC, Fisher S. Neurotics who fail to take their drugs. Br J Psychiatry. 1965;111(480):1043-1049.

21. Mori M. Social expectations of pharmacists and evaluation thereof, considering the issue of "leftover drugs". Chouzai to Joho. 2013;19(2):156-161 [In Japanese].

22. IMS Study Identifies Six Critical Levers to Improve Medicine Use and Avoid $\$ 500$ Billion in Unnecessary Annual Healthcare Spending IMS: http://www.imshealth.com/portal/site/ims (Accessed 7-Sep-2013). 